\title{
Consumers' views on nutrition and public health
}

\author{
BY KEES DE WINTER AND GABRIELA RODRIGUEZ
}

Bureau Européen des Unions de Consummateurs, Avenue de Tervueren, 36 bte 4, B-1040, Brussels, Belgium

The composition of the diet is closely linked with human health and well-being. Therefore, it is worthwhile to promote healthy eating habits. Over the last 50 years, diets have changed immensely in Western societies. Some of the changes, however, cannot be considered nutritional improvements. Morbidity and mortality due to diseases which are influenced by the composition of the diet have increased.

For a considerable time, the topics of malnutrition and micronutrient-deficiency diseases have been the main focus of nutrition science. Over the last few decades, a lot of research has been carried out on the composition of a balanced diet. In recent years, the concept of functional foods and the physiological effects of numerous non-nutritive substances have gained attention. In addition, the role of the 'old' micronutrients with regard to the diseases of affluent society is being increasingly studied. Methodologies to conduct studies to investigate the physiological effects of individual food components, such as fatty acids, monosaccharides and amino acids, have been developed. Nowadays, nutritional science touches on almost every element of foodstuffs.

Traditionally, food policy on the one hand has been aimed at guaranteeing a sufficient supply of safe and wholesome food and on the other hand aimed at promoting healthy food habits. The concept of wholesomeness indicates that the composition of foodstuffs is important for an adequate dietary intake and nutritional well-being, along with the safety of the products. Problems of malnutrition and micronutrient diseases continue to occur, even when adequate and varied food supplies are present (Food and Agriculture Organization, 1996). Food and nutrition information and education are recommended. Such activities could be linked to health promotion which provides a broader perspective than information and education alone. It implies that the context of behaviour is taken into account and that structural changes are considered which could improve dietary habits.

Growing physiological knowledge offers new possibilities for improvements of dietary intake (and the health) of the population. It creates opportunities for consumers and producers. Consumers can buy improved foodstuffs and producers can increase their sales through the manufacturing of products with added value. The market for functional products, which can make a positive contribution to overcoming our nutritional problems and achieving a healthy diet, is developing (Winkler, 1995). The rationale for these products makes sense in a culture increasingly aware of the old adage 'prevention is better than cure' (Tuley, 1997). For consumers it is essential not to spend extra money on products which do not constitute real benefits. They should be protected against unjustified statements in marketing. It should not be claimed or implied that a healthy diet cannot be achieved through customary foodstuffs.

\section{FORTIFICATION OF FOODSTUFFS, FOOD SUPPLEMENTS, NON-NUTRITIVE SUBSTANCES}

A sufficient intake of micronutrients is needed in order to prevent deficiencies and to maintain good health. Under normal physical conditions, a balanced diet provides sufficient amounts of almost all nutrients for the proper functioning of the body. Due to low 
natural amounts in foodstuffs or a specific physiological condition, intakes of nutrients by means of foodstuffs can, however, be inadequate. In such cases, insufficient intakes of essential components must be prevented by the use of food supplements or fortified products. For a long time, little was known about the health effects of elevated intakes of micronutrients and, therefore, many governments chose to follow a restrictive policy as regards the fortification of foodstuffs. Such a policy would avoid any risks of overconsumption.

Many countries have implemented obligatory food fortification policies for nutrients which are not present in sufficient amounts in everyday foodstuffs. Such policies prescribe that specific nutrients must be added to certain, generally consumed, foodstuffs; for example, the addition of vitamins $A$ and $D$ to margarine. In addition, food supplements are also offered for sale and an increasing number of countries allow voluntary fortification of various foodstuffs. Fortified foodstuffs and vitamin supplements contribute to preventing deficiencies which could emerge from poor dietary habits. The good vitamin status of the populations in Germany and Austria has been attributed to fortified foodstuffs (Elmadfa, 1996). In these countries, the quantity of a foodstuff normally consumed may contain a maximum of threefold the recommended daily allowance (RDA; Directorate-General Internal Market and Industrial Affairs, Report EUR, 1992) which minimizes the risks of overdose.

It has become evident that intakes of many vitamins considerably above the RDA (Directorate-General Internal Market and Industrial Affairs Report EUR, 1992) do not impose a danger to human health. For only a few vitamins (A, D, folic acid) the margins between the RDA and the safety level are relatively small. A tendency to accept more liberal practices on food fortification can be observed.

Claims for the health benefits of intakes of vitamins far above the RDA are increasingly made. In most cases, these claims are based on observations whereby two groups are compared. Such studies may provide indications about the possible relationship between vitamin intakes and health. Claims have been made concerning the prevention of cancers. However, the (US) National Research Council (1996) concluded that it could not find any firm proof concerning positive effects of an increased intake of micronutrients above the normal doses on the prevalence of cancer in human subjects. Although supplements and fortified products can help to overcome deficiencies, in most cases, the promotion of a varied diet is preferred as it is a more sustainable solution to prevent nutritional problems in the long term. In addition, the fortification of foodstuffs with micronutrients alone does not help to achieve an appropriate diet. Too much focus on vitamin intakes could distract consumers from more important problems related to diets rich in fats and refined products.

A large number of epidemiological studies have demonstrated protective effects of high intakes of fruit and vegetables against cancers and cardiovascular diseases (Watzl, 1996). Fruit and vegetables are rich sources of (antioxidant) vitamins and other substances with antioxidant properties. Protective effects of the antioxidant vitamins are assumed. However, intervention trials on the effects of increased vitamin intakes have not demonstrated that the beneficial health effects of abundant fruit and vegetable consumption could be replaced by increased intakes of particular vitamins. In the Alpha-Tocopherol, Beta-Carotene Trial, which took 8 years, it was even demonstrated that $\beta$-carotene supplements resulted in an $18 \%$ increase in lung cancer and an $8 \%$ increase in total mortality (Hennekes et al. 1994). In the US the Beta-Carotene Retinol Efficacy Trial was cut short, almost 2 years early, because the results indicated that the respondents who received vitamin supplements had an increased risk of developing lung cancer and of dying 
(see van Doormen, 1996). Intervention trials can prove that exposure causes a health effect. Most types of epidemiological studies can only identify associations (Langseth, 1996). Increased intakes of vitamin supplements have not been proven to give additional protection against lung cancer or cardiovascular diseases. Considering the available evidence, the US National Institute of Cancer does not advise people to take food supplements. They advise people to consume ample fruit and vegetables, and cereals and to stop smoking (Hennekes et al. 1994). The health benefits of diets rich in fruit and vegetables seem to be not only dependent on the amounts of micronutrients.

Plants do contain numerous (thousands) chemical components, i.e. secondary plant substances. These substances are present in small amounts and may exert a physiological effect in human subjects which can influence health. In a varied diet, the daily intake of these 'phytoactive' substances is on average $1.5-3 \mathrm{~g} / \mathrm{d}$ (Watzl, 1996). Some of these 'phytoactive' substances have shown anti-cancer, antioxidative, anti-microbial and antithrombotic effects. Substances that belong to this group are, for example, colouring substances such as anthocyanins and carotenoids (600 different substances) and substances such as saponins, glucosinolates, phenol acids and flavonoids. The cabbage family of vegetables, for example, contain many non-nutritive substances such as quercetin and other polyphenols; flavonoids and anthocyanins. The protective effects of vegetables are greater than those of fruit. In fruit, the contribution of vitamin $\mathrm{C}$ to the total antioxidant potential is approximately $15 \%$. The remainder can be attributed to the secondary plant substances (Watzl, 1996). Indeed, pure fruit juices may be more wholesome than lemonades fortified with vitamin $C$.

The combined physiological effects of micronutrients and the secondary plant substances could be responsible for the positive impact on human health of fruit and vegetable consumption. Could beneficial health effects be realized through increased intakes of isolated secondary plant substances? Answering this question is not easy, but considering current knowledge, the answer cannot be positive for the time being. Little is known about possible toxicity, damage, synergisms, bioavailability and optimal amounts of 'phytoactive' substances (Watzl, 1996). There are a large number of these substances and their interactions in the human body are often unknown. Antioxidants can turn into prooxidants. Vitamin supplements and/or supplements containing isolated secondary plant substances cannot replace good food habits.

The nutritional well-being of consumers would benefit from a rational selection of foodstuffs to achieve a balanced diet. Consumers should not be told otherwise. However, fortified foodstuffs and/or food supplements can help to provide sufficient micronutrients in particular cases such as low-energy diets. To date, claims about the health benefits of vitamin intakes far above the RDA are based on studies which can reveal associations only. Scientific evidence proving health benefits resulting from intakes of micronutrients (far) above the RDA, is lacking.

\section{FUNCTIONAL FOODS AND FOOD CLAIMS}

For functional foods it is alleged that they offer a positive effect on physiological functions in the human body. They can be products containing unsaturated fatty acids, amino acids, fibre, antioxidants, vitamins ( $\beta$-carotene and tocopherol) and minerals. Some can make a positive contribution; others are just marketing gimmicks (Winkler, 1995). Functional foods are intended to bring health benefits to the whole population. They can be distinguished from foodstuffs for particular nutritional use which aim to fulfil the dietary needs of consumers that have health problems. 
Many consumers are interested in the relationship between the composition of their diet and health, and they are willing to change their eating habits if this would provide an improvement to their health. This trend is reflected in the growing sales of products which are perceived to have physiological functional properties. Producers are eager to claim added value (and higher prices) for such products.

Consumers are confronted with a growing number of foodstuffs that claim to have favourable properties for their health. If claims are made, they must, of course, be based on scientific evidence demonstrating the alleged effect. The question arises as to whether it is wise to allow claims for individual products. Is it reasonable to promote individual foodstuffs as 'healthier' than other foodstuffs? 'In fact, there are no good or bad foods, per se, only good and bad diets' (Food and Agriculture Organization, 1996). Consumer groups believe that the promotion of individual products may divert the attention of consumers from the composition of the overall diet. Foodstuffs are only healthy in relation to the overall diet. Actually, the discussions about functional foods concentrate on the issue of substantiating claims and on the question of who should decide whether there is sufficient evidence to make a claim.

Claims for foodstuffs are a tool to draw attention to the relationship between nutrition and health. Claims must be complete, truthful and not false or misleading. Under EU law, rules for the use of claims have not been set, although advanced draft proposals have been prepared by the services of the European Commission. The July 1993 European Commission draft proposals (Commission of the European Communities, 1993) laid down comprehensive standards for numerical values for nutrient content claims (nutritional claims), comparable with the rules applied in the US (Food and Drug Administration, 1992). Quantified criteria for nutritional claims are necessary in the interest of consumers and to provide guidance to enforcement officers and producers. For example, claims such as low $\mathrm{Na}$ or reduced fat must have an unequivocal meaning. A survey of the Consumers' Association (1995) in the UK, revealed that $84 \%$ of consumers agreed that health messages and nutrition claims on foods should be regulated. The EU Scientific Committee for Foodstuffs, the EU Member States and consumer organizations have expressed favourable opinions towards the EU legislation for the adoption of numerical values for the use of nutritional claims. However, the European Commission is not intending to submit proposals for such legislation.

Unlike in the EU, rules for the use of health claims have been adopted in the USA. The USA has retained a restrictive system; health claims have to comply with a number of conditions laid down in the Nutrition Labelling and Education Act (NLEA; Food and Drug Administration, 1992) and it is up to the Food and Drug Administration (FDA) to decide whether a claim complies with the established conditions. In order to approve a claim, the FDA requires 'significant scientific agreement'. As yet eight health claims have been approved in the US. In several EU countries claims can be made if the person responsible is able to 'substantiate the claim'. The US approach provides better guarantees that health claims are based on the full body of scientific knowledge.

In some European countries strict rules are applied for the use of health claims and in others lax rules are applied. A lax approach would be to accept one study as sufficient evidence to permit a claim. Generally-accepted scientific evidence is never based on one study. Blood cholesterol-lowering effects of yoghurt had been claimed in three studies, but could finally not be sustained (Sanders, 1993). The FDA requires 'significant agreement among qualified experts supported by the total of publicly available evidence'. Indeed, only expert committees are equipped to decide whether sufficient justification for a claim is available. Consumer groups believe that approval of health claims should be required 
before sale. Leaving the making of health claims to the manufacturer's discretion, and enforcement officers to then decide whether the claim is misleading, is an undesirable approach. Independent scientific expertise must form the grounds for judgements on the acceptance of claims.

As there are no good or bad foods, per se, the use of product-related health claims is to be questioned. Such claims could convey the message to consumers that an appropriate diet could be replaced by eating particular products. For example, rules published in January 1997 in Sweden do not allow product-related claims at all (Tuley, 1997). If health claims are permitted, these should preferably be generic claims. In the USA, most of the allowed health claims are generic claims, for example, the claim regarding diets low in saturated fat and cholesterol and the risk of heart disease, and the claim linking the consumption of fruit and vegetables with the prevention of cancer. Such claims contribute to the education of consumers about the relationship between diet and disease. The NLEA in the USA also has established a number of nutritional requirements dealing with the presence and absence of nutrients, to which products must conform if a health claim is made. In conclusion, consumer protection in the USA with regard to the use of food claims is advanced. EC legislation on the use of food claims is badly needed in order to protect European consumers from being misled and deceived.

\section{FAT AND SUGAR SUBSTITUTES}

An increase in body weight and the prevalence of obesity is rising in many European and Asian countries, as well as in Canada and the USA. Over the last decade, the increase in obesity has been more rapid in many places than it has been before (Geerts, 1996). Also in the younger age-group, a remarkable increase in obesity is observed for which a sedentary lifestyle is surely partly responsible. Although the number of obese people has grown quickly, consumption surveys do not indicate that people eat more on average. Obesity can be associated with a number of major health hazards such as CHD and diabetes mellitus.

An increasing number of food products is being developed that contain less fat or sugar. Could those products contribute to improving nutrition? A number of studies on the effects of consumption of low-energy products have indicated that replacement of products with a high fat content with products with a reduced fat content diminishes the energy and fat intake (van het Hof et al. 1996). The consumption of foodstuffs with a low fat content could contribute to the prevention of body-weight increase and the prevention of obesity. The consumption of low-fat products can indirectly lead to an overall increase in carbohydrate intake. Potentially, this could help prevent diet-related diseases. Consumer organizations welcome the development of low-fat products.

Fat substitutes are often based on conventional ingredients which have undergone specific processing. In this respect, the product 'Olestra' is an exception, as it consists of a new chemical entity. The US consumer group, Center for Science in the Public Interest, has published the White Paper on Olestra (Karstadt \& Jacobson, 1996) indicating serious consumer problems with this product: carotenoid depletion, reduction in the absorption of fat-soluble vitamins, A, D, E and $\mathrm{K}$, gastrointestinal disturbances, possible carcinogenicity and the absence of a safety margin. Furthermore consumer groups outside the USA will oppose the introduction of this product.

In Western diets, mono- and disaccharides provide about $20 \%$ of total energy. Theoretically, about one-third of the sugar intake can be replaced by intense sweeteners which do not deliver energy. Will the use of intense sweeteners diminish energy intake and help to prevent obesity? Studies in which simple carbohydrates were 
replaced by intense sweeteners (covert replacement studies) showed an initial rapid decrease in food intake which tended to revert towards normal (Renwick, 1994). This implies that simple carbohydrates, when removed from the diet, are replaced by foodstuffs in which either carbohydrates, fats and proteins are likely to be present. As a result, the relative contribution of fats in the diet rises.

Evidence is accumulating that for fat, carbohydrates and protein, different physiological food-intake control mechanisms are active in the human body (Blaak \& Saris, 1995). The carbohydrate balance is likely to be under stricter metabolic and hormonal controls than those for protein and fat. When the body's carbohydrate stores are sufficiently satisfied, a feeling of satiety is obtained. Furthermore, under customary dietary conditions, lipid synthesis from carbohydrate does not occur to a large extent. Excess glucose will be stored as the glucose polymer glycogen in both liver and skeletal muscle, providing a rapid energy source. There are indications that carbohydrate, as well as protein stores, are regulated with the excess being metabolized, whereas excess fat intake is channelled directly into fat stores. 'Excess carbohydrate promotes its own oxidation by stimulation of the cellular uptake and oxidation of glucose. It has been demonstrated that over a 9 hour period the same amounts of carbohydrates, fat and protein are oxidised whether or not the test meal is supplemented with extra fat, indicating that fat intake does not promote its own oxidation.' (Blaak \& Saris, 1995). Thus, if sugars in the diet are replaced by fats it will be more difficult to maintain a stable body weight. A positive relationship has been observed between the fat content of the diet and body weight, and a negative relationship between the amount of sugar consumed and body weight (BoltonSmith \& Woodward, 1994). This observation has been confirmed in several other studies. Fat substitutes seem more effective than sugar substitutes in contributing to body-weight control (De Graaf, 1996).

The behaviour of fats in the human body is noteworthy. For the release of fat from fat cells, the so-called $\beta$-adrenal receptors on the plasma membrane must be stimulated. Consequently, fat is released and can be utilized in the body. Obese subjects are often less likely to release fat from fat cells; thus, they are less inclined to lose body fat. Subjects with a predisposition to store fat would benefit, therefore, from a diet containing relatively large amounts of carbohydrates, as this would increase energy expenditure and inhibit fat accumulation. A recent study has indicated that women genetically predisposed to obesity are more likely to gain weight on a high-fat diet (Heitmann et al. 1995). As indicated previously, it is likely that the use of artificial sweeteners may result in an increase in the proportion of fat in the diet. This questions their contribution to maintaining a stable bodyweight. Unfortunately, no long-term studies have been published on the effects of artificial sweeteners (De Graaf, 1996). For the benefit of consumers, such studies should be conducted and used to reconsider existing legislation on the conditions of use for sweeteners.

\section{FOOD BIOTECHNOLOGY}

Gene technology in the area of food is developing quickly. Enzymes produced from genetically-modified organisms are already widely used. Products from modified crops are entering the market-place. As yet, most applications in crops concern herbicide or insect resistance. Custom-designed crops will be developed in the near future. The development of salt-, drought- or temperature-adapted varieties has been promised, but it is not expected in the short or medium term. The application of biotechnology is claimed to lead to energy savings, less use of chemicals, and to better-quality foodstuffs (Harlander, 1989). 
Since gene technology involves the deliberate transfer of genetic material between unrelated species, it offers increased opportunities for breeding. Moreover, gene technology relates to food safety, biodiversity, the protection of the environment, ethics, and to political and socio-economical issues. Consumer surveys indicate that most people know little about the use of gene technology in food production and have a limited knowledge of the possible benefits of using gene technology in food production. Overall, the acceptance of gene technology in food production is relatively low. Other new technologies are believed to contribute more to improvement of the quality of life than gene technology (Marlier, 1992). Better knowledge on the part of consumers does not necessarily lead to a more positive attitude towards biotechnology; but to a less-supportive attitude towards some applications; for example, the use of bovine somatotropin in milkproducing cows. More knowledge may lead to increased support for applications which are considered beneficial, since consumer attitudes are influenced by perceived usefulness. The use of herbicide-resistant crops is perceived more positive if it will result in a reduction in pesticide use rather than being considered to be primarily beneficial to industry.

The attitudes of consumers towards gene technology are also influenced by the regulations in place and the control of these regulations by the responsible authorities. Both in the EU and the USA, over $80 \%$ of the respondents in surveys indicated that gene technology should be regulated (Office of Technology Assessment, US Congress, 1987; Dixon, 1991). Without a trustworthy legislation, gene technology might not develop at all. In addition, the application of gene technology must be subjected to strict controls. Recently, the Bureau Européen des Unions de Consommateurs welcomed the adoption of the Novel Foods and Novel Food Ingredients Regulation (EC, 1997), which provides a basis to evaluate the safety of novel food products.

\section{CHANGING EATING HABITS}

The relationship between diet and health is increasingly addressed in research. For example, the EC programme on life sciences in Fifth Framework Research Programme (European Commission, 1996) pays considerable attention to this topic. This research will result in better understanding of the relationship between the composition of the diet and health. Increased knowledge can lead to the development of products with improved nutritional properties such as infant formulas with a better-adapted fatty acid composition. Another example concerns the development of margarines low in saturated and trans-fatty acids. In The Netherlands, a reduction in the amount of trans-fatty acids in margarines has been calculated to result in a reduction in the risk of cardiovascular disease of about $5 \%$ (Katan, 1995).

Many newly developed products are convenience foods which fit well into modern busy lifestyles with irregular working hours and the trend to spend less time preparing food. However, many of these products contain only small amounts of fruit and vegetables, and consequently phytoactive substances and micronutrients. Comparative tests of consumer organizations have indicated that 'ready-to-eat meals' commonly contain only a small amount of vegetables. It is a challenge to develop new products that combine wholesomeness and convenience.

Consumers want food that smells and tastes good and that has a good appearance. If these conditions are fulfilled, consumers may take health into account. Many people want to eat healthily but they encounter difficulties in doing so. In a survey (Institute of European Food Studies, 1996) $70 \%$ of the respondents in Europe (fifteen EU Member States) thought that their diet was already healthy. Most respondents knew that healthy 
eating involves eating less fat and eating more fruit and vegetables. A survey in The Netherlands pointed out that only $5 \%$ of the respondents thought that they ate too much fat; only $2 \%$ thought they ate more fat than the average person (Brug et al. 1993). All over Europe, most people believe that they are eating healthily; many do not seem to have a realistic opinion about their actual food intake.

Extensive evidence indicates that much of the EU diet could be very significantly improved through reducing fat intake and increasing fruit and vegetables intake and by reducing the prevalence of overweight (Institute of European Food Studies, 1996). For example, a study in Germany indicated a $50 \%$ lower breast-cancer risk in a group with average vegetable daily intake of $523 \mathrm{~g}$ compared with that of a group with an intake of $276 \mathrm{~g}$ vegetables. The risk of strokes was reduced by $60 \%$ at a high intake of vegetables (Watzl, 1996).

All available data confirm and reinforce the advantages for human health of a balanced diet containing plenty of fruit, vegetables and cereals, and of reducing the amount of fat in the diet. Based on the available epidemiological studies, the US Government recommends a consumption of 400-600 g vegetables daily, which comprises three to five portions, and two to three pieces of fruit (US Department of Agriculture, US Department of Health and Human Services, 1996). At the moment, the actual intakes in the USA are far below these recommendations.

In Germany, people consume on average $200 \mathrm{~g}$ vegetables per d, which is $83 \mathrm{~kg}$ per year. In Italy, people consume on average $180 \mathrm{~kg}$ vegetables per year, in Spain $190 \mathrm{~kg}$ per year and in Greece $230 \mathrm{~kg}$ per year (Watzl, 1996). Moreover, data indicate that the intake of fruit and vegetables is decreasing in several EU Member States, especially among young and poor people. In The Netherlands, food intake studies conducted in 1987-8 and 1992 revealed that the average consumption of fruit and vegetables had decreased between 5 and $10 \%$. The amounts consumed only decreased slightly for people above 50 years. For all other groups of the population a considerable reduction could be observed. Furthermore, with regard to fruit intake, a remarkable reduction in consumption could be observed for people under 50 years old (van der Weijden, 1995). Some of the reasons for this decrease are: the use of ready-to-eat meals that contain few vegetables; the use of snacks other than fruit; more food is consumed between meals and meals are therefore smaller; the influence of children; more relaxed attitude towards food preparation; decreasing knowledge of vegetables.

Knowledge about food and nutrition should be disseminated on a large scale. People should become aware that it is not always justified to believe that they are eating healthily. Improvement of dietary habits should be placed in a broader perspective.

\section{CONCLUSIONS}

A balanced diet can be achieved by consuming a varied diet consisting of wholesome foodstuffs with a high nutrient density. Such a diet should contain a considerable amount of fruit and vegetables, and cereals. The health benefits of a balanced diet cannot be attained through the consumption of food supplements, fortified foodstuffs, functional foods or phytoactive substances alone. The role of these products in the improvement of the diet can only be supplementary. Within the EU, there is an urgent need to adopt legislation dealing with nutritional and health claims. This legislation could be based on the existing legislation in place in the USA. Low-fat foods may offer benefits to consumers who want to reduce their fat intake. The effects of the use of artificial sweeteners on body-weight maintenance are unclear, thus long-term studies should be conducted. The use of modern 
biotechnology must be subject to strict legislation and controls. Education and information campaigns on food and nutrition should primarily focus on the need to eat more fruit and vegetables, and starchy products.

\section{REFERENCES}

Blaak, E. E. \& Saris, W. H. M. (1995). Health aspects of various digestible carbohydrates. Nutrition Research 15, 1547-1573.

Bolton-Smith, C. \& Woodward, M. (1994). Dietary composition and fat to sugar ratios in relation to obesity. International Journal of Obesity 18, 820-828.

Brug, J., Riedstra, M., Pruyn, J. F. A. \& Löwik, M. R. H. (1993). Effecten van derde landelijke Let op Vet Campagne (Effects of Third World campaign: be aware of your fat intake). Voeding 57, 8-10.

Commission of European Communities (1993). Draft Proposal for a Council Directive on the Use of Claims Relating to Foodstuffs. Doc. SPA/62/Rev.3. Brussels: Commission of the European Communities.

Consumers' Association (1995). Are you confused by food labelling? Which August issue, 14-17.

de Graaf, C. (1996). Effectiviteit van vet-en suikervervangers (Effectiveness of fat and sugar replacers). Voeding 57, 22-25.

Directorate-General Internal Market and Industrial Affairs, Report EUR (1992). Food-Science and Techniques. Reports of the Scientific Committee for Food, Nutrition and Energy Intakes for the European Community. Brussels: Commission of the European Communities.

Dixon, B. (1991). Biotechnology: a plus according to European poll. Biotechnology 9, 16.

EC (1997). European Union Regulation (EC) no. 258/97 of the European Parliament and of the Council of 27 January 1997 concerning novel foods and novel food ingredients. Official Journal of European Communities L43.

Elmadfa, I. (1996). Nährstoffpille oder Lebensmittel - Sind sie wirklich gleichwertig (Nutrient supplement or foodstuff - Are they equal in value)? In Schöne neue Zukunft - auch für Lebensmittel (Beautiful New Future Also for Foodstuffs)? Bonn: AgV.

European Commission (1996). The Commission's Proposal for the Fifth Framework Programme (1998-2002). Eur 17651. Brussels: Commission of European Communities.

Food and Agriculture Organization (1996). Get the Best from Your Food. A New FAO Initiative in Nutrition Education for the Public. Rome: FAO.

Food and Drug Administration (1992). The New Food Label. FDA Backgrounder, HFI40. Washington, DC: Department of Health and Human Services.

Geerts, A. (1996). Prevalentie van Obesitas in Nederland Neemt Toe (Prevalence of obesity in The Netherlands is increasing). Voedingsmagazine 9, 20-22.

Harlander, S. K. (1989). Food biotechnology: yesterday, today and tomorrow. Food Technology 43, 196.

Heitmann, B. L., Lissner, L., Sorensen, T. I. A. \& Bengtsson, C. (1995). Dietary fat intake and weight gain in women genetically predisposed for obesity. American Journal of Clinical Nutrition 61, 1213-1217.

Hennekes, C. H., Buring, J. E. \& Peto, R. (1994). Antioxidant vitamins - benefits not yet proved. New England Journal of Medicine 330, 1081-1082.

Institute of European Food Studies (1996). A pan-EU survey of Consumer Attitudes to Food, Nutrition and Health. Dublin: Institute of European Food Studies.

Katan, M. B. (1995). Exit trans fatty acids (commentary). Lancet 346, 1245-1246.

Karstadt, M. \& Jacobson, M. F. (1996). White Paper on Olestra. Washington, DC: Center of Science in the Public Interest.

Langseth, L. (1996). Nutritional Epidemiology: Possibilities and Limitations. ILSI Europe Concise Monograph Series. Brussels: ILSI Europe.

Marlier, E. (1992). Biotechnology and Genetic Engineering. What Europeans Think About it in 1993. Eurobarometer 39. 1. Brussels: Commission of the European Community.

National Research Council (1996). Carcinogens and Anticarcinogens in the Human Diet. A Comparison of Naturally Occurring and Synthetic Substances. Washington, DC: National Academy Press.

Office of Technology Assessment, US Congress (1987). New Developments in Biotechnology: Public Perceptions of Biotechnology. Washington, DC: US Government Printing Office.

Renwick, A. G. (1994). Intense sweeteners, food intake, and the weight of a body of evidence. Physiology and Behaviour 55, 139-143.

Sanders, M. E. (1993). Summary of conclusions from a consensus panel of experts on health attributes of lactic cultures: significance of fluid products containing cultures. Journal of Dairy Science 76, 18191829.

Tuley, L. (1997). Join the health club. The Journal on food and drink ingredients: International Food Ingredients 1, 24-28. 
US Department of Agriculture, US Department of Health and Human Services (1996). Nutrition and Your Health: Dietary Guidelines for Americans, 4th ed. Washington, DC: Department of Health and Human Services.

van Doormen, P. (1996). Vitamin A increases the chance of cancer in heavy smokers. De Standaard 20 January. van der Weijden, M. (1995). Groot deel bevolking eet te weinig groente en fruit (A large part of the population does not eat enough fruit and vegetables). Voeding 56, 10-13.

van het Hof, K. H., Weststrate, J. A., de Graaf, C., Zimmermanns, N. J. H., van den Berg, H., Velthuis-te Wierik, E. J. M., Westerterp, K. R., Westerterp-Plantenga, M. \& Werboeket-van de Venne, W. P. H. G. (1996). Met light geen energetische compensatie (No energy compensation when light products are used). Voeding 57, 3233.

Watzl, B. (1996). Bioaktive Substanzen - Reicht der Gerhalt Unserer Lebensmittel nich aus? (Bioactive substances - is the amount in our foods sufficient?). In Schöne neue Zukunft - auch für Lebensmittel (Beautiful New Future - Also for Foodstuffs)? Bonn: AgV.

Winkler, J. T. (1995). A Background Paper: Consumer Issues and Functional Foods. London: National Food Alliance. 